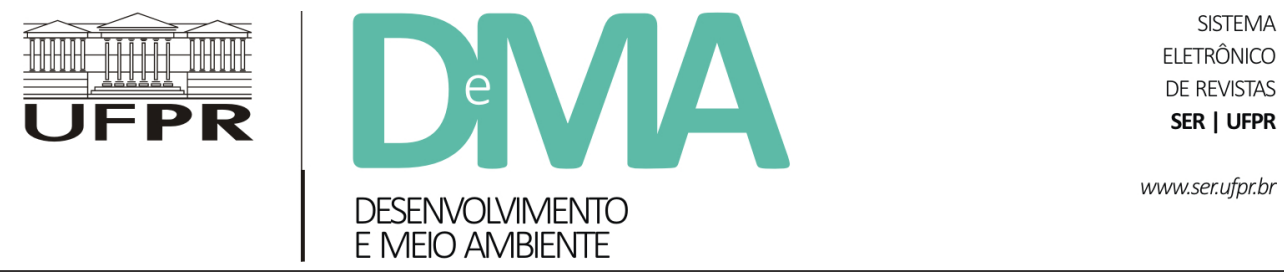

\title{
Regulação e hidropolítica na fronteira Brasil-Paraguai
}

\section{Regulation and hydropolitics in the Brazil-Paraguay frontier}

\author{
Aline Robles BRITO ${ }^{1 *}$, Fabrício José MISSIO² \\ ${ }^{1}$ Programa de Pós graduação em Desenvolvimento Regional e de Sistemas Produtivos (PPGDRS), Universidade Estadual de Mato Grosso do \\ Sul (UEMS), Ponta Porã, MS, Brasil. \\ ${ }^{2}$ Departamento de Economia, Universidade Federal de Minas Gerais (UFMG), Belo Horizonte, MG, Brasil. \\ *E-mail de contato: alinerobles.brito@gmail.com
}

Artigo recebido em 6 de março de 2019, versão final aceita em 24 de setembro de 2019.

RESUMO: $\quad$ As relações entre Brasil e Paraguai são dotadas de particularidades históricas, sociais, culturais, políticas e econômicas que resultaram em situações de cooperação e conflito no decorrer dos anos. A proximidade geográfica desses países impõe interdependência e vulnerabilidades, exigindo interações cotidianas, como é o caso do uso compartilhado dos recursos hídricos transfronteiriços. Diante disso, o principal objetivo deste artigo é traçar um panorama acerca do gerenciamento político das águas transfronteiriças no Brasil e no Paraguai. A principal conclusão é de que existem fragilidades nas relações entre os países, que quando somadas à interdependência hidrológica e a importância dos recursos hídricos na atual conjuntura ambiental, tornam o futuro do cenário hidropolítico vulnerável e instável, especialmente nessa fronteira internacional.

Palavras-chave: recursos hídricos transfronteiriços; gestão hídrica partilhada; hidropolítica.

ABSTRACT: Brazil and Paraguay have historical, social, cultural, political and economic particularities that resulted in situations of cooperation and conflict over the years. Geographic proximity imposes interdependence and vulnerability and requires daily interactions, such as in the shared use of transboundary water resources. Therefore, the main objective of this article is to draw a panorama about the political management of transboundary waters in Brazil and Paraguay. The main conclusion points to the existence of weaknesses in relations between countries, which when added to hydrologic interdependencies and the importance of water resources in the current environmental debate make the future of the hydro-political vulnerable and unstable, especially at this international border.

Keywords: transboundary water resources; shared water management; hydro-political. 


\section{Introdução}

No contexto das relações internacionais gerir adequadamente os recursos hídricos sempre foi de grande relevância, seja na demarcação de fronteiras, na navegabilidade ou mesmo na realização de projetos e iniciativas de desenvolvimento envolvendo diferentes segmentos produtivos (uso doméstico, industrial, agrícola, energético, entre outros). Evidentemente, somam-se a isso as múltiplas finalidades que esses recursos têm para com a preservação da vida no planeta e as crescentes preocupações quanto a sustentabilidade ambiental.

Com o aumento populacional, o crescimento econômico e a poluição ambiental, os países têm se deparado (em diferentes graus) com à iminência de uma provável escassez hídrica e com a inevitável interdependência hidrológica. Essa interdependência pode ser entendida como as relações de dependências mútuas entre os diversos sistemas hídricos que se encontram distribuídos pelo planeta.

As complicações que surgem dessa relação de dependência estão relacionadas ao fato de que cada país tem soberania sobre a utilização de seu território e dos seus recursos. Entretanto, como esses podem ser transfronteiriços, a forma de gestão utilizada em um determinado país gera efeitos (diretos ou indiretos) em outros países. Fica evidente que a distribuição geográfica destes recursos pode resultar no surgimento de problemas e conflitos hídricos, especialmente entre os países que são limítrofes.

Em um mundo globalizado, ao mesmo tempo em que a gestão dos recursos está sujeita a soberania nacional, os países buscam maior inserção no sistema internacional. E, portanto, eles precisam atuar de forma condizente com os fundamentos do Direito Internacional Ambiental (Guerra, 2007; Sola, 2015).
Nesse sentido, lidar com esse contexto complexo, interdependente e vulnerável pode ser considerado como o principal desafio na gestão hídrica, principalmente no caso das "águas superficiais ou freáticas que marcam, atravessam ou se encontram situadas nas fronteiras entre dois ou mais Estados" (GWP, 2015, p. 33).

Segundo Tatemoto (2011), as relações estabelecidas entre os países vizinhos são constituídas sob preceitos que variam conforme o sistema internacional se impõe na realidade política e econômica de cada país. Ou seja, em termos gerais, apesar do sistema internacional ser altamente competitivo, ele também exige a cooperação entre os países para que os conflitos de interesses sejam mediados de forma pacífica e diplomática.

Sendo assim, a questão da hidropolítica torna-se cada vez mais atual. Em termos conceituais, isso pode ser entendido como a "capacidade de instituições geopolíticas manejarem os recursos hídricos compartilhados de forma politicamente sustentável, isto é, sem tensões ou conflitos entre as entidades políticas" (GWP, 2015, p. 20).

Esse tema é relevante para a América do Sul de forma especial, pois o continente destaca-se por ter uma das maiores reservas hídricas do mundo, aproximadamente $26 \%$ do volume total existente. A maior parte destas reservas são de águas transfronteiriças, que referem-se às águas, superficiais e subterrâneas, que atravessam as fronteiras políticas de dois ou mais Estados nacionais (PNUD, 2006).

Nesse sentido, o presente estudo busca traçar um panorama acerca do gerenciamento político das águas transfronteiriças entre Brasil e Paraguai. Coloca-se a importância de compreender as normativas legais e os acordos jurídicos estabelecidos, ou seja, o posicionamento político que cada país assume em torno da gestão hídrica em seu território e, especialmente, em suas áreas de fronteira. 
Além disso, deve-se levar em consideração que as relações internacionais entre Brasil e Paraguai, historicamente, passaram da cooperação para o conflito, da solidariedade para a contradição, configurando elementos fundamentais na constituição de ambos países (Gemelli \& Souza, 2011). Entre os principais acontecimentos, certamente, a Guerra da Tríplice Aliança, a construção da Ponte Internacional da Amizade e da Hidrelétrica Binacional de Itaipu foram os mais marcantes e retratam bem a intensidade e a complexidade nas relações de vizinhança entre os dois países.

A Guerra do Paraguai ou a Guerra da Tríplice Aliança (1864-1870) foi o maior conflito armado e sangrento do continente sul-americano. Entre suas diversas motivações, a principal delas aponta para um impasse político acerca do compartilhamento hídrico diante de tensões nas relações diplomáticas inerentes à navegabilidade na região do Rio da Prata, que envolveu, ainda, a Argentina e o Uruguai, mas certamente teve maiores implicações, econômicas e sociais, para o Brasil e o Paraguai (Abente, 1987; Mota, 1995; Doratioto, 2012).

Depois de um longo período após o término da Guerra, em 1965, foi inaugurada a Ponte Internacional da Amizade que fica localizada em Foz do Iguaçu (PR-BR) e Cidade do Leste (Alto Paraná-PY). A iniciativa representou um avanço nas relações comerciais entre os dois países com vistas a estreitar os laços de cooperação, por meio da facilitação do tráfego e circulação de serviços, pessoas, produtos e veículos (Guimarães \& Souza, 2010). Contudo, apesar dessa obra ser considerada o primeiro grande passo no rompimento das limitações e atrasos na região, a integração entre os países ainda não está livre de conflitos e problemas.

Com a construção da Usina Itaipu Binacional, que aconteceu entre os anos 1975 a 1982, localizada no Rio Paraná, as interações comerciais foram inten- sificadas e tornaram-se cruciais para o crescimento econômico de ambos os países. Cabe destacar que essa aproximação também foi a solução de um impasse diplomático (que existia antes mesmo da guerra do Paraguai) envolvendo a disputa pela posse das terras do Salto de Sete Quedas, área em que hoje se localiza o lago da usina (Itaipu, 2018).

Atualmente, as relações entre Brasil e Paraguai são pacíficas e diplomáticas, embora essas relações sejam pautas sempre presente em debates políticos, principalmente naqueles relacionados à segurança pública. Uma das primeiras lembranças que vem à mente quando se faz referência a fronteira Brasil-Paraguai, em grande parte reforçada pelos meios de comunicação, são os problemas relacionados ao tráfico de drogas, ao contrabando de mercadorias e ao bandidismo sem punição (Oliveira, 2008). Ressalta-se que são incipientes os debates envolvendo outras temáticas, especificamente àquelas de cunho ambiental.

Para cumprir com os objetivos, o escopo metodológico deste estudo classifica-se em descritivo e exploratório, fundamentado em bases bibliográficas (livros, teses, dissertações e artigos) de diversas áreas do conhecimento (Ciência Política, Geografia Humana, Relações Internacionais, entre outras) e documentais (leis, acordos e tratados internacionais, políticas e/ou ações direcionadas para às águas fronteiriças).

Assim, o artigo estrutura-se em três seções, além desta Introdução e das Considerações Finais. As seções 2 e 3 discutem o gerenciamento dos recursos hídricos transfronteiriços no Brasil e no Paraguai, respectivamente. Na seção 4, empreende-se uma análise crítica acerca das especificidades, possibilidades de conflitos e a efetividade das ações de cooperação para fortalecimento da hidropolítica direcionada especificamente à fronteira entre Brasil e Paraguai. 


\section{Gestão dos recursos hídricos transfronteiriços no Brasil}

O Brasil pode ser considerado um país privilegiado em função de sua disponibilidade de água doce, constituindo a maior reserva do mundo, aproximadamente $12 \%$ do total (ABC, 2014). Dado a sua dimensão continental, há uma significativa variabilidade climática anual e sazonal nas suas cinco regiões administrativas (Norte, Nordeste, Sul, Sudeste e Centro Oeste). Essa variação do clima é um dos principais condicionantes da disponibilidade hídrica nestas regiões, o que também acaba interferindo na sustentabilidade das atividades socioeconômicas de cada região (Tucci et al., 2001).

O gerenciamento dos recursos hídricos no país é dividido em 12 grandes regiões hidrográficas definidas pelo Conselho Nacional de Recursos Hídricos (CNRH) por meio da Resolução $n^{\circ} 32$ no ano de 2003 - visando apoiar o planejamento hídrico em escala nacional. São elas: a Região Amazônica, Região do Atlântico Nordeste Ocidental, Região do Atlântico Nordeste Oriental, Região do Parnaíba, Região do Tocantins Araguaia, Região do São Francisco, Região do Atlântico Leste, Região do Atlântico Sudeste, Região do Paraguai, Região do Paraná, Região do Uruguai, Região do Atlântico Sul (ANA, 2017).

O Ministério do Meio Ambiente (MMA) atua como órgão superior do Executivo nacional nos assuntos relacionados aos recursos hídricos por meio da Secretaria de Recursos Hídricos e Ambiente Urbano (SRHU), especificamente via Departamento de Recursos Hídricos (DRH). A SRHU possui funções fundamentais e que determinam toda a organização do setor hídrico no país. A primeira função refere-se à responsabilidade na formulação do Plano Nacional de Recursos Hídricos (PNRH) e, a segunda, consiste em subsidiar o Orçamento para a União (MMA, 2018).

Os Comitês de Bacia Hidrográfica (CBH) são os órgãos colegiados com atribuições normativas, deliberativas e consultivas a partir de uma jurisdição específica. Eles desempenham um papel fundamental na descentralização da gestão hídrica do país, ao propiciar a participação dos usuários e das comunidades específicas e delimitadas à área de determinada bacia hidrográfica. Esses Comitês contam com o apoio técnico de suas respectivas Agências de Água e são constituídos por representantes da União, dos estados e do Distrito Federal cujos territórios se situem, ainda que parcialmente, em suas respectivas áreas de atuação. No caso dos Comitês de bacias de rios fronteiriços e transfronteiriços que têm a gestão compartilhada com outro país, a União deve incluir um representante do Ministério das Relações Exteriores-MRE (Brasil, 1997). Toda essa articulação entre a União, unidades federativas e municípios ocorre por meio do Sistema Nacional de Gerenciamento de Recursos Hídricos (SINGREH), mostrado na Figura 1 abaixo:

Outro ponto a ser destacado é que a partir da Constituição Federal (CF) de 1988 as águas passaram a ser de domínio público, ou seja, todos têm direito ao seu uso. Para isso, foram estabelecidos dois domínios: um da União (em relação aos corpos de água que atravessam mais de um estado e/ ou país); e outro dos estados (em relação às águas subterrâneas) (MMA/SRHU, 2007). Todavia, isso gera uma inconsistência institucional, pois no caso de águas subterrâneas internacionais, especificamente, ocorre uma sobreposição de competências, dado que a gestão das águas transfronteiriças é de 
competência exclusiva da União (art. 20, inciso III da $\mathrm{CF} / 88$ ). Os estados ficam responsáveis especificamente pelo domínio das águas subterrâneas ou superficiais, fluentes, emergentes e em depósito (art. 26, inciso I) (Brasil, 2008).

Em relação ao cenário geral das diversas bacias, grupo de bacias ou microbacias que compõem o espaço territorial de todas as regiões hidrográficas do Brasil, três delas são de maior relevância, principalmente sob o aspecto de "disponibilidade de recursos hídricos, reserva estratégica de águas e economia regional e nacional" (ABC, 2014, p. 5). São elas a bacia Amazônica; a bacia do Rio da Prata; e a bacia do Rio São Francisco. As duas primeiras, somadas às outras bacias menores (a do Oiapoque e a do Lagoa Mirim), extrapolam o território nacional e estendem-se aos territórios de 10 países vizinhos. A Figura 2 mostra a localização das bacias transfronteiriças.

Nessas bacias hidrográficas transfronteiriças, $\mathrm{o}$ país acaba reunindo um total de 83 rios fronteiriços ou transfronteiriços, como mostra a Tabela 1.

As águas subterrâneas transfronteiriças do Brasil também são relevantes. Ressalta-se, assim sendo, a distribuição hídrica heterogênea em todo o país, que possui regiões que contam com uma grande disponibilidade (como o Aquífero Guarani ao Sul) e também outras com baixa disponibilidade (como os aquíferos das rochas cristalinas ao Nordeste) (ABC, 2014). A Tabela 2 apresenta informações mais específicas sobre os aquíferos transfronteiriços no Brasil:

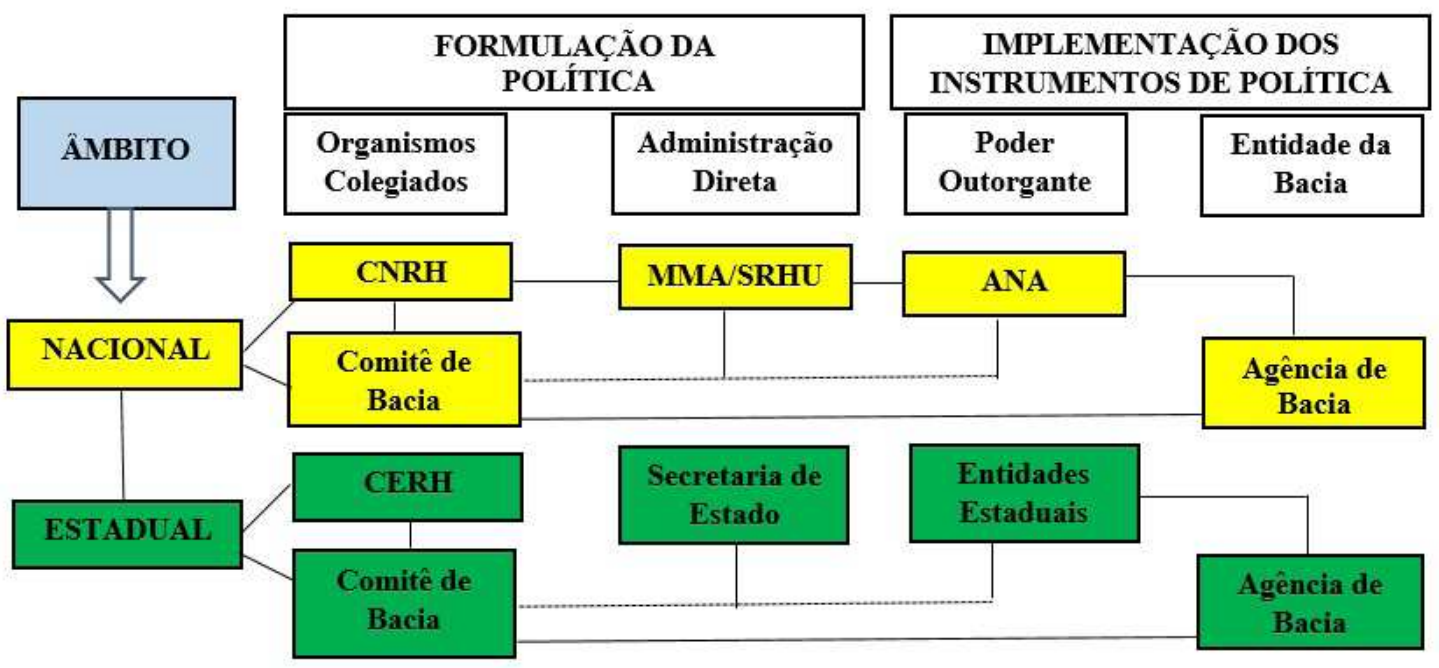

FIGURA 1 - Sistema Nacional de Gerenciamento de Recursos Hídricos e suas instâncias de atuação no Brasil. FONTE: Adaptado de ANA (2018). 


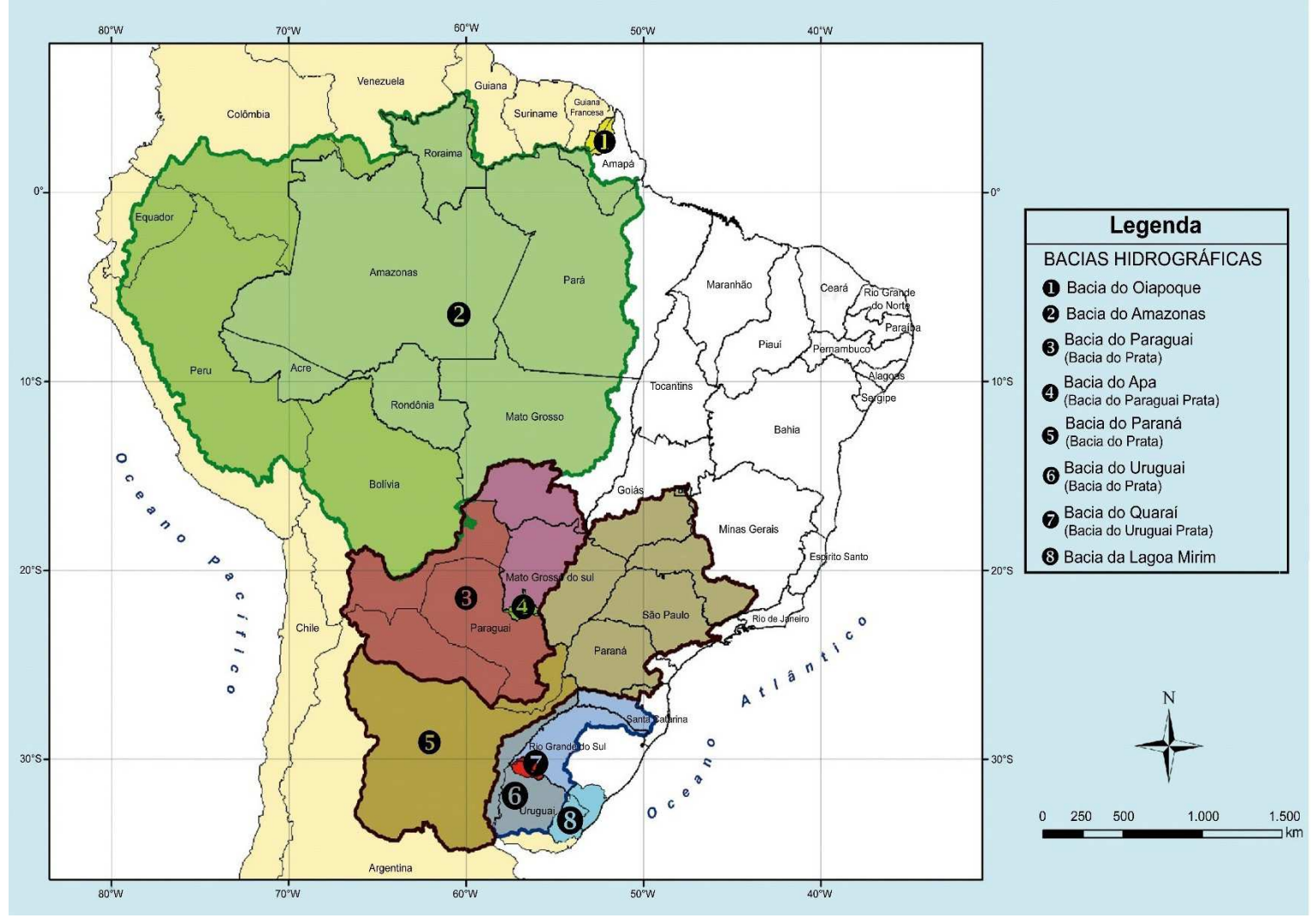

FIGURA 2 - Bacias hidrográficas transfronteiriças do Brasil.

FONTE: Adaptado de Brasil (2013, p. 10).

TABELA 1 - Relação de rios fronteiriços ou transfronteiriços do Brasil com os países vizinhos.

\begin{tabular}{cccc}
\hline Países vizinhos & $\begin{array}{c}\mathbf{N}^{\circ}(*) \text { de rios fronteiriços ou } \\
\text { transfronteiriços }\end{array}$ & Países vizinhos & $\begin{array}{c}\mathbf{N}^{\circ}(*) \text { de rios fronteiriços ou trans- } \\
\text { fronteiriços }\end{array}$ \\
\hline Guiana Francesa & 2 & Bolívia-Paraguai & 1 \\
Guiana & 3 & Paraguai & 3 \\
Venezuela-Colômbia & 1 & Argentina-Paraguai & 1 \\
Colômbia & 22 & Argentina & 4 \\
Colômbia-Peru & 1 & Argentina-Uruguai & \\
Peru & 19 & Uruguai & 8 \\
Bolívia & 17 & & \\
\hline
\end{tabular}

FONTE: Adaptado de Brasil (2013).

NOTA: *Esse levantamento foi feito com mapeamento na escala de 1:1. 000.000, mas caso a escala utilizada fosse menor, é muito provável que vários outros corpos d'água em região de fronteira fossem identificados, especialmente na região amazônica. 
TABELA 2 - Aquíferos transfronteiriços no Brasil.

\begin{tabular}{|c|c|c|c|}
\hline NOME & PAIISES COMPREENDIDOS & $\begin{array}{l}\text { EXTENSÃO } \\
\left(\mathrm{km}^{2} \text { aprox.) }\right.\end{array}$ & $\begin{array}{l}\text { \% no Brasil } \\
\text { (aprox.) }\end{array}$ \\
\hline 1) Amazonas* & $\begin{array}{l}\text { Bolívia, Brasil, Colômbia, Equador, Peru, Vene- } \\
\text { zuela }\end{array}$ & 3.950 .000 & - \\
\hline 2) Aquidauana & Brasil, Paraguai & 27.000 & 54,00 \\
\hline 3) Boa Vista-Serra do Tucano & Brasil, Guiana & 24.000 & 60,00 \\
\hline 6) Guarani & Argentina, Brasil, Paraguai, Uruguai & 1.087 .879 & 61,65 \\
\hline 7) Litorâneo-Chuí & Brasil, Uruguai & 41.000 & 80,00 \\
\hline 8) Pantanal & Bolívia, Brasil, Paraguai & 130.000 & 80,00 \\
\hline 9) Permo-Carbonífero & Brasil, Uruguai & 41.000 & 51,00 \\
\hline
\end{tabular}

(*) Antigo Sistema Solimões-Içá, incluindo a formação Alter do Chão. FONTE: Brasil (2013, p. 25).

Apesar dessa abundância, é preciso ressaltar que há um tipo de cegueira hídrica (Folegatti et al., 2010) que precisa ser urgentemente enfrentada pelo Brasil, pois apesar de abundantes, os recursos hídricos brasileiros estão distribuídos de forma desigual no território, espacial e temporalmente. Esse cenário demanda atenção especial a fim de evitar problemas na qualidade da água bem como no surgimento de áreas de conflitos (ANA, 2017). Ademais, grande parte desses recursos são compartilhados internacionalmente. $\mathrm{O}$ gerenciamento dos recursos hídricos fronteiriços ou transfronteiriços é baseado no marco regulatório e no escopo jurídico-legal do Brasil e dos seus estados fronteiriços (apresentados no Apêndice 1).

Um ponto importante a ser destacado na gestão dos recursos hídricos transfronteiriços é a criação da Câmara Técnica de Gestão de Recursos Hídricos Transfronteiriços (CTGRHT) em 2000, integrada por 17 membros, composta por seis representantes de órgãos do governo federal, um de conselhos dos estados de Santa Catarina e Rio Grande do Sul, quatro de usuários), um de comitês de bacias hidrográficas, um de consórcios e associações intermunicipais, um de organizações técnicas, um de organizações de ensino e pesquisa e dois de organizações não-governamentais (Brasil, 2013, p. 37).

Os membros são devidamente eleitos pelo CNRH com as seguintes competências: i) propor mecanismos de intercâmbio técnicos, legais e institucionais entre países vizinhos, nas questões relacionadas com gestão de recursos hídricos; ii) analisar e propor ações conjuntas visando minimizar ou solucionar os eventuais conflitos; iii) propor diretrizes para gestão de recursos hídricos fronteiriços e transfronteiriços; iv) discutir os problemas visando desenvolver ações e implementar soluções comuns, buscando otimização e alocação de recursos huma- 
nos e financeiros; v) propor ações mitigadoras e compensatórias; e vi) as competências constantes do Regimento Interno do CNRH e outras que vierem a ser delegadas pelo seu Plenário (CNRH, 2000).

Souza \& Versieux (2015) em uma análise ampla voltada às relações internacionais de cooperação que vêm sendo estabelecidas pelo Brasil, especificamente por meio da Agência Nacional das Águas (ANA), com os vizinhos sul-americanos, identificaram que o país tem uma postura proativa e cooperativa. Os autores sugerem que o Brasil ocupa um papel importante na disseminação de conhecimento e técnicas para a gestão dos recursos hídricos e um papel estratégico, com vistas a diminuir o surgimento de externalidades negativas. É preciso salientar que em algumas situações, como no caso da bacia da Amazônia, o país ocupa uma posição jusante na bacia hidrográfica. Segundo os autores,

[...] a política externa brasileira não apenas expressa clareza quanto à condição de interdependência entre os atores dos assuntos ambientais, como também quanto à necessidade da resolução das questões ambientais para a promoção de melhores condições sociais e econômicas no sistema internacional. O Brasil, portanto, assume um papel de protagonista na cooperação ambiental internacional, responsabilizando-se por custos para o provimento de respostas às questões ambientais nos seus diversos subsetores [...] (Souza \& Versieux, 2015, p. 126).

No âmbito das relações internacionais, o Brasil mantém inúmeros acordos e tratados para a cooperação internacional com os países vizinhos. Apesar de esses acordos terem surgidos, inicialmente, direcionados às questões da navegação, às obras hidráulicas, à integração econômica e ao desenvolvimento, atualmente eles têm sido aplicados também na gestão harmônica, na proteção ambiental e na sustentabilidade hídrica (Broch, 2008; UNESCO/ OEA, 2008; Brasil, 2013). Alguns desses acordos, tratados e convênios internacionais firmados pelo Brasil encontram-se sintetizados no Apêndice 2.

Diante dessas informações, mesmo considerando as finalidades diversas e os contextos específicos, é possível concluir que a gestão compartilhada dos recursos hídricos entre o Brasil e seus vizinhos tem sido trabalhada ao longo dos anos, o que tem evitado o surgimento de conflitos mais extremados entre os países.

No entanto, cabe ressaltar que na década de 1960 iniciou-se uma situação de difícil resolução com a Argentina envolvendo a construção da Usina Binacional de Itaipu. O país vizinho mantinha posição contrária ao projeto binacional entre Brasil e Paraguai, afirmando que, em caso de uma catástrofe, o seu território seria afetado. O impasse foi solucionado por meio do Acordo Tripartite, no dia 19 de outubro de 1979, que delineou algumas regras e especificações técnicas para a construção de Itaipu garantindo certa segurança para a Argentina (Ferres, 2004).

Em resumo, pode-se classificar os tratados vigentes no Brasil em três grandes grupos: i) aqueles com princípios e regras norteadores para posterior conclusão de novos acordos ou uso das águas (Tratado da Bacia do Prata, Tratado de Cooperação Amazônica); ii) aqueles com foco em um único tipo de uso das águas (Itaipu, Uruguai); e iii) os tratados focados na gestão local de pequenas sub-bacias hidrográficas (Lagoa Mirim, Quaraí e Apa) (Brasil, 2013).

Assim, conclui-se que o país conta com uma estrutura operacional interna consolidada (ao menos 
na teoria) para gerenciar, controlar e monitorar o uso e a qualidade dos seus recursos hídricos transfronteiriços. Além disso, o país tem criado mecanismos para fomentar uma gestão descentralizada, democrática (via a CTGRHT e os CBH) e direcionada às realidades específicas e locais.

Evidentemente, existem vários pontos a serem melhorados para que a gestão compartilhada dos recursos hídricos seja realmente efetiva. Por exemplo, como visto, existem divergências nos processos de compartilhamento das águas em domínio federal e estadual determinados pela própria constituição brasileira. A próxima seção trata do gerenciamento dos recursos hídricos transfronteiriços no Paraguai.

\section{Gestão dos recursos hídricos transfronteiriços no Paraguai}

Todo o território paraguaio pertence à grande Bacia do Prata (Figura 3). A Bacia do Prata é a segunda maior estrutura hidrográfica do continente sul-americano (equivalente a $17 \%$ da superfície) e é de suma importância em função de sua amplitude, dos fluxos que produz e pelos recursos naturais. Ela faz fronteira com cinco países, apresentando-se fundamental para o abastecimento do Paraguai (Crespo \& Luraghi, 2000; Queiroz, 2012). Com uma extensão de 3,1 milhões de $\mathrm{km}^{2}$, essa bacia compreende ainda o Sul do Brasil, o Sudeste da Bolívia, grande parte do Uruguai e uma ampla zona do centro e norte da Argentina (CIC PLATA, 2011).

O Paraguai é dividido em duas grandes regiões geográficas: a Região Oriental e a Região Ocidental ou Chaco, tendo o Rio Paraguai como o divisor natural dessas regiões (Broch, 2008). A primeira é a mais favorecida em termos hídricos e está locali- zada entre os rios Paraná e Paraguai, contando com um regime pluvial generoso, condições climáticas favoráveis e águas com profundidade, quantidade e qualidade considerável (Crespo \& Luraghi, 2000). Isso torna o Paraguai um país com grande riqueza hídrica, entre águas subterrâneas e superficiais. Contudo, os recursos hídricos estão distribuídos de forma heterogênea e as águas consideradas de boa qualidade encontram-se apenas na região oriental. Na região ocidental além de certa escassez, a água é salobra (Broch, 2008).

Em termos de águas superficiais, o Paraguai se encontra localizado sob três grandes sub-bacias hidrográficas, a do Rio Paraguai que compreende todo o Chaco e a metade Oeste da Região Oriental, a Bacia do Rio Paraná, a parte Leste da Região Oriental e a do Rio Pilcomayo, localizada no sudeste da região Ocidental (Broch, 2008, p. 110). O país também conta com amplos aquíferos, são eles: Caacupé, Coronel Oviedo, Independência, Missiones, Patiño, Alto Paraná e o Yrendá. Destes, dois são compartilhados com outros países: o aquífero de Missiones, com Argentina, Brasil e Uruguai e o Yrendá, localizado no Chaco central, compartilhado com Argentina e Bolívia (FUNDAINGE, 2004).

No que se refere ao gerenciamento dos recursos hídricos no Paraguai, a Constituição Federal de 1992 não prevê especificidades para a gestão hídrica transfronteiriça. Entretanto, consta (art. 163) que é atribuição de cada Departamento (estado) coordenar as atividades e serviços comuns, juntamente com suas respectivas Municipalidades (prefeituras), tais como: obras públicas, provisão de energia, de água potável e demais serviços intermunicipais, bem como promover a cooperação entre eles (Paraguay, 1992). 


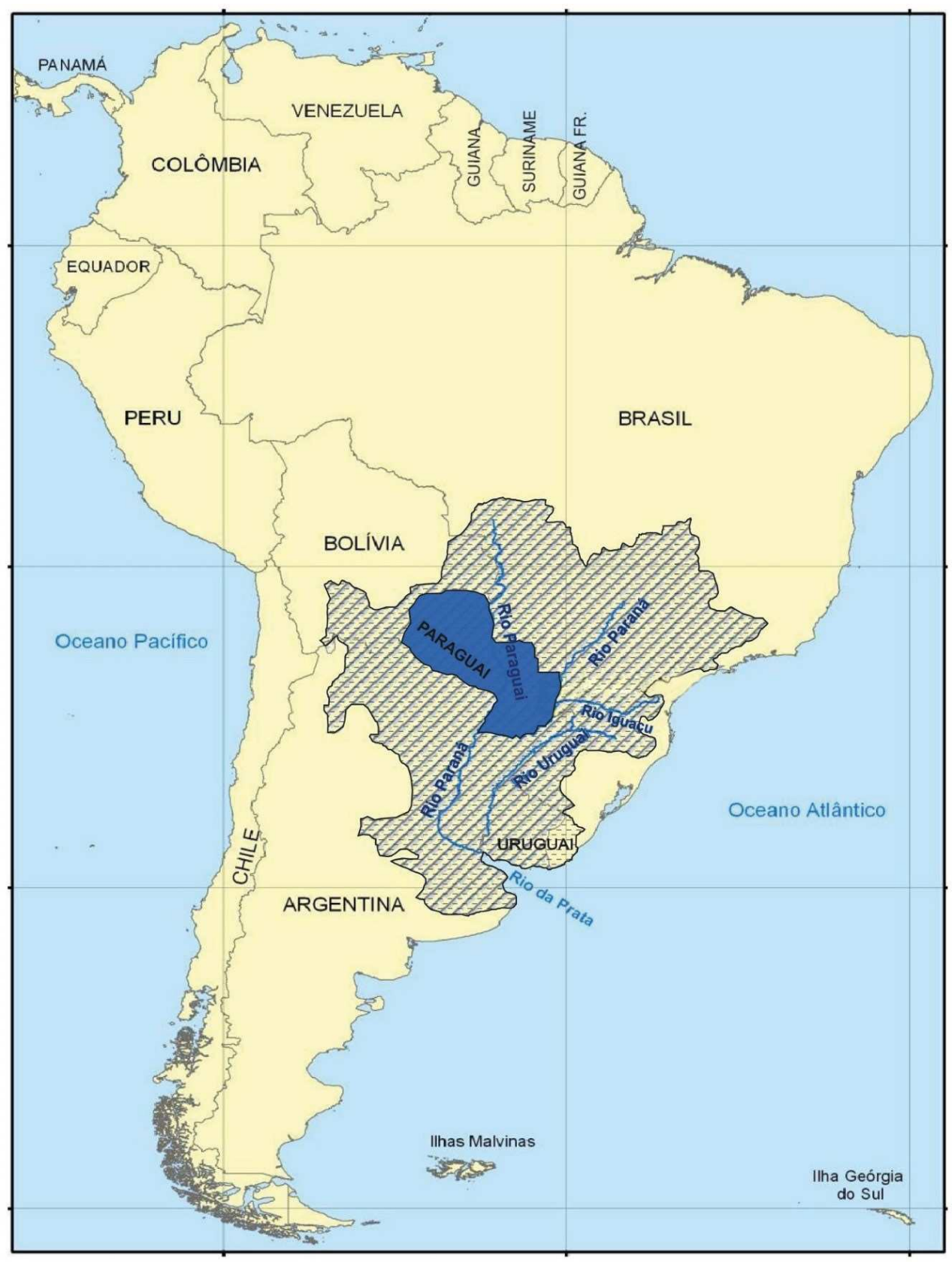

FIGURA 3 - Localização do Paraguai na Bacia do Prata. FONTE: Adaptado de Carneiro Filho (2013, p. 27). 
Em relação às águas transfronteiriças, de forma específica, o único aspecto legal identificado é que a gestão desses recursos está condicionada à competência do Ministério das Relações Exteriores (MRE). O ministério possui a competência de gerir os projetos, programas e acordos no âmbito internacional, realizando o acompanhamento dos acordos vinculados aos recursos hídricos. Ressalta-se que este é um trabalho em conjunto com a Secretaria do Ambiente (SEAM), que tem dentre suas funções, especificamente por meio da Diretoria Geral de Proteção e Conservação dos Recursos Hídricos (DGPCRH), a responsabilidade técnica de elaborar, coordenar e fomentar a operacionalização de tais ações (UNESCO/OEA, 2008).

No âmbito interno, foi apenas por meio da criação da lei no 3.239 sancionada no dia 10 de julho de 2007 - conhecida como a Lei dos Recursos Hídricos do Paraguai - que o país começou a contar com uma lei específica para a gestão sustentável e integral de todos os seus recursos hídricos. Todavia, essa lei não foi regulamentada até o momento. Através dessa lei, o país estabelece (ao menos na esfera legal) uma diretriz para a gestão das águas que são compartilhadas com outros países, art. 8, ao determinar que os recursos hídricos transfronteiriços devem ser regidos e normatizados por tratados, convênios e acordos internacionais, após aprovação e ratificação pelo Congresso Nacional (Paraguay, 2007). Atualmente, é possível observar certos avanços nesse sentido (Apêndice 3).

Percebe-se que no âmbito das relações internacionais, o Paraguai tem buscado estabelecer algumas relações de cooperação com seus vizinhos a fim de aproveitar as potencialidades geograficamente impostas. Além disso, o país considera essa riqueza natural como estratégia para uma maior integração econômica, ambiental e social no cenário sul-americano.

Entretanto, é preciso destacar que até a criação da Lei n ${ }^{\circ} 3.239 / 07$, a estrutura administrativa interna do Paraguai passou por diversas incongruências e ações descoordenadas, que permanecem até os dias atuais, com a ausência da regulamentação da referida lei. Segundo Haurón et al. (2017), a legislação sobre a utilização dos recursos hídricos no país encontra-se dispersa em diferentes órgãos e documentos reguladores, entre estes: o Código Civil, o Código Rural e em várias leis municipais e departamentais direcionadas ao funcionamento do sistema hidrológico do país.

Facetti (2014) argumenta que a discrepância no gerenciamento do setor hídrico do Paraguai estabeleceu-se no início dos anos 1990. Várias tentativas de reformas no setor, incluindo mudanças estruturais e institucionais para cumprir normas e leis foram implementadas, sendo uma delas aquela que definiu a separação entre as funções de regulação e gestão. $\mathrm{O}$ autor destaca que havia uma sobreposição entre os organismos responsáveis e competentes pela gestão da água no país, que somados às leis inconsistentes e dispersas no setor, implicava que os responsáveis atuassem em projetos e planos de forma individualizada e descoordenada. Dessa forma, o setor hídrico caminhou no decorrer dos anos sem um "guia" para coordenar os esforços e as necessidades reais tornando o setor deficiente e objeto de desafio até os dias atuais (Facetti, 2014).

Em termos do gerenciamento interno, as funções das principais organizações envolvidas na gestão hídrica do Paraguai, o denominado setor de Água Potável e Saneamento (APYS), estão definidas e sintetizadas na Tabela 3. 
TABELA 3 - Ambiente organizacional referente à gestão dos Recursos Hídricos no Paraguai.

\section{ORGANIZAÇÕES}

- Secretaria do Ambiente (SEAM)

[Criada pela Lei Federal $n^{\circ} 1.561$ do dia

29 de maio de 2000]

- Diretoria Geral de Proteção e Conservação dos Recursos Hídricos (DGPCRH) [Criada pela Lei Federal $\mathrm{n}^{\circ} 1.561$ do dia 29 de maio de $2000-$ artigo 25]

- Serviço Nacional de Saneamento Ambiental (SENASA)

[Criado pela Lei n ${ }^{\circ} 369$ de 1 de dezembro de 1972, ampliada pela Lei ${ }^{\circ}$ 908 de 4 de julho de 1996]

- Direção Geral de Saúde Ambiental (DIGESA)

- Empresa de Serviços Sanitários do Paraguai SA (ESSAP)

[Criada pelo Decreto $N^{\circ} 16.636 / 02$, que se originou da Lei $\mathrm{N}^{\circ} 2.44 / 54$ de criação da CORPOSANA]

\section{- Ente Regulador de Serviços Sani- tários do Paraguai (ERSSAN) \\ [Criado pela Lei $\mathrm{n}^{\circ} 1.614$ em 02 de novembro de 2000 , e regulamentado pelo decreto $\left.n^{\circ} 18.880 / 2002\right]$}

\section{- Diretoria de Água Potável e Sane- amento (DAPSAN)}

[Criada através do Decreto 5.369 de 8 de novembro de 2010, que substituiu a Unidade dos serviços de Água Potável e Esgoto Sanitário (USAPAS)

\section{FUNÇÕES DESEMPENHADAS}

É uma entidade governamental, com status de Ministério. Possui as funções de formular, coordenar, executar e fiscalizar a política ambiental nacional, que atua conforme as diretrizes estabelecidas na Política Ambiental Nacional (PAN) do Paraguai, aprovadas pelo Conselho Nacional do Ambiente (CONAM). É composta por várias diretorias com funções específicas subdivididas por áreas temáticas.

Órgão vinculado à SEAM, que tem as seguintes competências: formular, coordenar e traçar políticas de manutenção e conservação dos recursos hídricos e suas bacias, assegurando o processo de manutenção das fontes básicas das correntes de água, a capacidade de reabastecimento dos aquíferos, o cuidado dos usos e o aproveitamento dos recursos hídricos, preservando o equilíbrio ecológico.
É um organismo técnico do Ministério de Saúde Pública e Bem estar Social (MSPyBS) e tem como principais funções: o planejamento, execução e supervisão das atividades de saneamento ambiental, relacionadas com a provisão de água potável, drenagem em zonas rurais e em localidades que tenham um número igual ou menor que 10 mil habitantes, sejam urbanas ou rurais.

Também é um organismo técnico do MSPyBS que tem a função principal de implementar as diretrizes do Código Sanitário e em tudo que se refere a qualidade ambiental, no estabelecimento de normas técnicas a respeito da qualidade da água potável e no controle de qualidade dos recursos hídricos.

É uma sociedade anônima constituída em 2002, a partir de uma organização estatal (CORPOSANA - Cooperação de Obras sanitárias da Cidade de Asunción). Possui as seguintes funções: prover os serviços de água potável para cidades com população superior a 10 mil habitantes, desde a captação e tratamento de água bruta, até o armazenamento, transporte, condução, distribuição e comercialização de água potável. Vale ressaltar que após a constituição da então ESSAP, houve uma incorporação de dívidas pelo Estado oriundas da anterior CORPOSANA e esta passou a ser uma entidade mista, que apesar de operar de forma descentralizada, atua em um regime de cumprimento de normas determinadas para Entidades Descentralizadas do Estado na aquisição de bens e contratação de serviços, fiscalizadas pelo Ministério da Fazenda (Ministerio de Hacienda - MH).

É uma entidade autárquica, com personalidade jurídica e dependente do Poder Executivo. Suas principais funções são regular a prestação de serviços de água potável e esgoto sanitário, supervisionar a qualidade e eficiência desses serviços, além de proteger os interesses da comunidade e dos usuários, controlando e verificando a oferta aplicação da disposições vigentes no que se refere a sua competência.

A DAPSAN é um órgão dependente do Ministério de Obras Públicas e Comunicações (MOPC), responsável pelo planejamento estratégico, estabelecimento de metas de expansão e melhorias da qualidade dos serviços hídricos. Sua criação substituiu a USAPAS, que foi uma das principais ações realizadas pelo MOPC para a implementação de políticas públicas voltadas para o setor hídrico, era considerada como um organismo técnico de apoio ao Poder Executivo que em 2010 passou a ser uma Diretoria do MOPC.

São organizações de direito privado, que contam com o apoio direto do SENASA na construção e no financiamento dos sistemas de água e esgoto em localidades com menos de 10 mil habitantes, rurais ou urbanas. Todavia, após a finalização das construções, as JSA’s se encarregam da operacionalização e manutenção, sendo as responsáveis pela prestação dos serviços, sem nenhuma dependência orçamentária ou financeira do SENASA. Os membros da Comissão Diretora das JSA são eleitos pela própria comunidade através de uma "assembleia de vizinhos", com exceção de um que é designado pelo governo municipal, A Comissão é composta de 5 a 9 membros, que não recebem remuneração de nenhuma natureza. As JSA são consideradas uma forma exitosa de prestação de serviço de água e esgoto sanitário e correspondem a 36,4\% da participação total do país. 
São operadores privados e independentes que manejam pequenos sistemas de produção hídrica - Sistemas privados ou "Aguateiros" que medem cerca de 300 conexões cada um. Antes da criação da ERSSAN, os aguateiros não precisavam de permissão e nem seguiam normas de controle de qualidade e totalizavam cerca de 1.400. Atualmente, esses operadores totalizam menos da metade, mas ainda são importantes para o abastecimento de cerca de $13,2 \%$ da população, principalmente rural.

FONTE: Adaptado de Fernández et al. (2010); Haurón et al. (2017); Broch (2008); FUNDAINGE (2004); GWP/SAMTAC, 2005.

Diante tantas organizações, fica evidente que o gerenciamento hídrico no Paraguai conta com a interferência de vários órgãos reguladores e vários tipos de prestadores de serviço (ESSAP, aguateiros, Juntas de Saneamento), ou seja, são múltiplos os órgãos de abastecimento. Certamente isto, somado às normativas legais e jurídicas relativamente recentes, pode justificar a falta de efetividade e a inconsistência no ambiente institucional, pois cada uma das organizações possuem atribuições e responsabilidades distintas. Além disso, observa-se que tais normativas estão dispersas em várias disposições e medidas legais, onde cada uma atende normas e contratos específicos e distintos.

$\mathrm{Na}$ Figura 4, pode-se compreender, de forma sintetizada, como ocorrem as inter-relações entre as organizações do setor hídrico paraguaio.

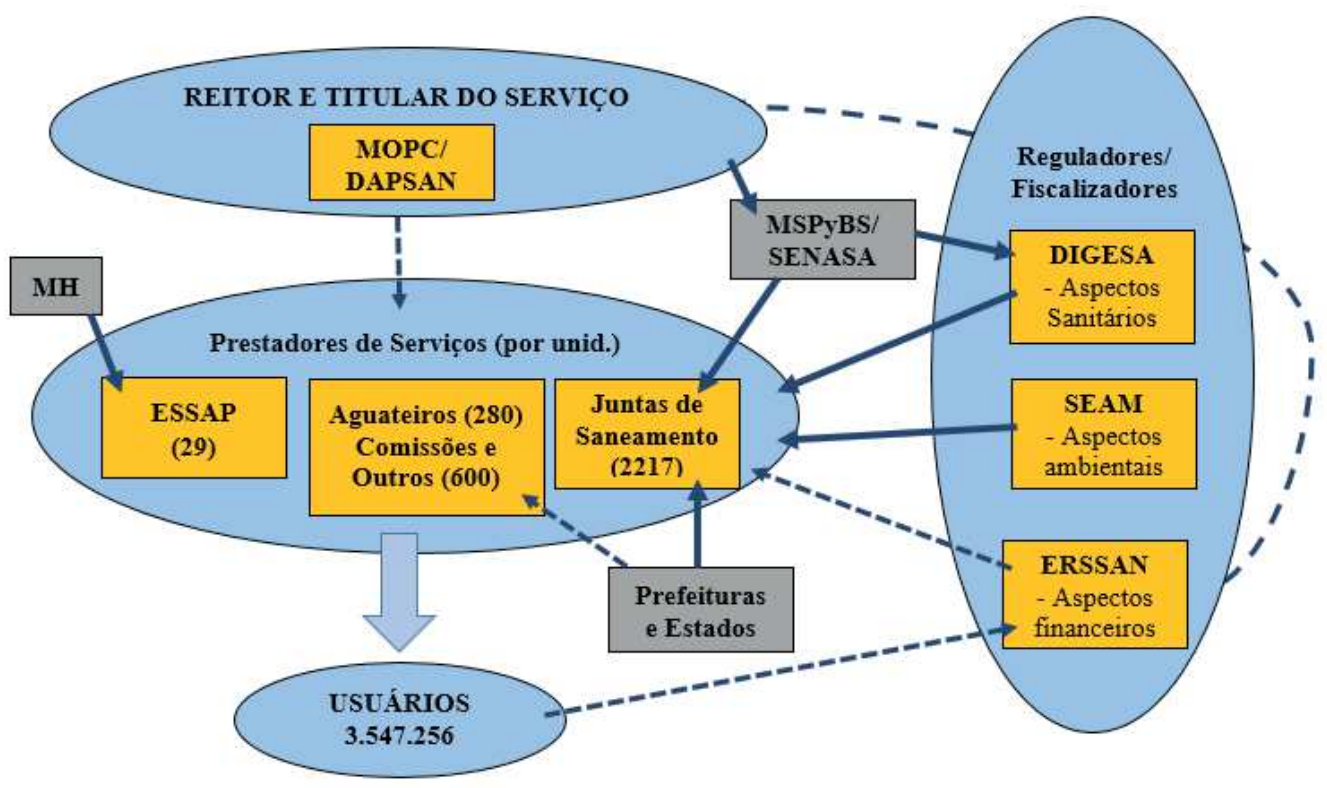

FIGURA 4 - Esquema das inter-relações existentes no setor de Água Potável e Saneamento do Paraguai FONTE: Adaptado de MOPC (2012, p. 12). 
Destaca-se que entre os prestadores de serviços há a carência de um contrato ou norma uniforme, pois não existe um documento único e formal com as diretrizes e as responsabilidades baseadas nos princípios constitucionais. Entretanto, é fundamental ressaltar que a existência desses diferentes tipos de prestadores possibilitou a provisão de água em diversas localidades, especialmente àquelas rurais, diante da incapacidade estatal de fazê-lo (Fernández et al., 2010).

Para Haurón et al. (2017), as entidades governamentais do país estabelecem normas sobre as diversas formas de uso da água, mas falta conexão e coordenação entre elas. Isso dificulta a governabilidade e a fiscalização e ainda possibilita a criação de novas leis devido à ausência de uma estrutura institucional parametrizada e um marco legal para unificar e direcionar ações para garantir o uso e a qualidade das águas.

Em outras palavras, apesar da existência de várias organizações e suas respectivas funções, o setor de APYS do Paraguai carece de adaptações internas para solucionar os problemas institucionais que são resultantes da falta de compatibilidade nas orientações políticas entre os responsáveis pelo gerenciamento hídrico no país. Nesse aspecto, Broch (2008) enfatiza que um ponto relevante sobre a gestão hídrica interna do Paraguai é que, apesar de existirem alguns instrumentos legais, até o momento não existe um sistema de informação dos recursos hídricos consolidado, tanto para as águas superficiais como para as subterrâneas. Acredita-se que a sistematização de todas as informações sobre os recursos hídricos seria um importante instrumento de gestão e melhoraria do ambiente de gerenciamento interno do setor no país, uma vez que contribuiria para o monitoramento, a disseminação e direcionamento de ações entre as distintas instituições.

Outro ponto que merece destaque é que o Paraguai não possui um Plano Nacional de Recursos
Hídricos (PNRH), o qual é crucial para estabelecer diretrizes, metas e estratégias para a gestão das águas. Sobre isso, Broch (2008) afirma que na Conferência em Johannesburgo sobre Desenvolvimento Sustentável, em 2002, os países participantes definiram metas específicas para a gestão hídrica. Nessa ocasião, houve o comprometimento com a elaboração do PNRH até 2005, o que não foi concretizado pelo Paraguai.

A falta de estrutura no setor hídrico se apresenta como uma justificativa para a não elaboração do PNRH (Facetti, 2014). Nesse sentido, foi apenas com a criação da Lei dos Recursos Hídricos, em 2007, que a SEAM teve as suas atribuições definidas, sendo então considerada como a Autoridade Nacional das Águas. Facetti acrescenta que a SEAM estava obrigada a apresentar até o ano de 2012, além do Plano Nacional, um Inventário Nacional das Águas e um Balanço Hídrico Nacional. Todavia, isso também não se concretizou.

Para Haurón et al. (2017), é notável a necessidade da apresentação de dados e mapas sobre a criticidade ambiental dos recursos hídricos no Paraguai. Isso só seria possível se houvesse um sistema de informação transparente e acessível ao público, ou também a elaboração do plano nacional, o qual englobasse as estratégias e os passos a serem seguidos para melhorar a governabilidade e o uso sustentável da água no país.

Em síntese, pode-se afirmar que ocorreram importantes avanços no Paraguai com o estabelecimento da Lei ${ }^{0}$ 3.239/07 e de certas instituições, porém, ainda são observadas ações inconsistentes, descoordenadas e insuficientes para o controle efetivo e monitoramento dos recursos hídricos. Portanto, no atual contexto, o gerenciamento dos recursos hídricos no Paraguai encontra-se com sérias debilidades, internas e externas. 
Salas Dueñas (2015) realiza uma análise da problemática da água no Paraguai e conclui que a deficiência em informações, falta de políticas claras, a multiplicidade de instâncias públicas além da pouca efetividade dos entes de controle e regulação são os principais pontos negativos. Segundo o autor, é preciso dar atenção a esses fatores internos, pois podem multiplicar-se ao levar em consideração a iminência da escassez dos recursos hídricos em todo o mundo.

Por fim, é possível destacar dois aspectos principais acerca da gestão hídrica paraguaia: i) há uma fragilidade do âmbito institucional interno - por exemplo, existe a escassez de fomento a projetos técnicos locais e a formulação de ações, metas e estratégias para todos os níveis governamentais que poderiam auxiliar no controle contínuo dos recursos hídricos; ii) verifica-se a multiplicidade nas inter-relações entre as várias prestadoras e reguladoras, indicando que sem uma base de diretrizes consolidadas e unificadas é possível que a fiscalização e o controle efetivo de todo o gerenciamento do setor hídrico paraguaio fique comprometido.

\section{Hidropolítica na fronteira Brasil- Paraguai}

Em termos gerais, gerenciar águas transfronteiriças nas fronteiras tem sido uma árdua tarefa aos governantes, pois utiliza-se normalmente a bacia hidrográfica como unidade de gestão e planejamento hídrico. No caso das águas internacionais isso tem se mostrado desafiador, pois

[...] há o temor de que a unidade territorial a ser gerenciada represente, na prática, a possibilidade de comprometimento da soberania e do interesse nacional sobre parte do território em que a área de drenagem do corpo hídrico compartilhado esteja. Assim, [...] requererá a construção de um arcabouço jurídico e institucional bi, tri ou multilateral, por meio de tratados e acordos, que ao mesmo tempo assegurem a soberania do território, a busca do interesse nacional e viabilizem o planejamento compartilhado, nos marcos da sustentabilidade ambiental e da fraternidade entre os povos da América do Sul. (Brasil, 2013, p. 35, grifo nosso).

Nesse sentido, uma efetiva gestão compartilhada entre diferentes países e instituições exigirá ainda, além de cooperação e integração, que sejam tomadas medidas jurídicas e legais inovadoras, tanto em âmbito local e internacional e

[...] envolverá, também, as questões de âmbito político e administrativo ligadas à política internacional, ao relacionamento bilateral entre os dois países e às políticas públicas específicas para áreas de fronteira. Na prática, exigirá efetiva integração e cooperação, de forma harmônica, entre diferentes níveis e órgãos de gestão, monitoramento e informações dos países envolvidos, incluindo, onde houver, a participação dos comitês de bacia hidrográfica e das comissões bilaterais mistas (Brasil, 2013, p. 36, grifo nosso).

Mais especificamente, é preciso destacar que o gerenciamento dos recursos hídricos transfronteiriços no Brasil e no Paraguai, apesar de apresentar algumas similaridades estruturais, encontram-se em estágios distintos, já que há diferenças significativas na implementação de suas políticas hídricas (Tabela 4).

É evidente que, além dos desníveis no marco legal, existem discrepâncias jurisdicionais na forma com a qual as águas são gerenciadas internamente 
nos dois países. O que é algo totalmente compreensível em razão da soberania de cada nação e, portanto, da constituição de suas próprias instituições. Porém, isso pode apresentar sérios problemas visto que a interdependência hidrológica pode se acentuar nas áreas de fronteiras, especialmente nas cidades conurbadas internacionalmente.

Muller (2005) afirma que nos municípios conurbados internacionalmente diversas relações transpassam os limites geopolíticos, tornando-se complexas e desafiadoras. Principalmente quando se referem a definição de direitos e de deveres (relacionados com as atividades sociais, econômicas, culturais ou políticas) observados pelos agentes públicos em ambos os Estados-nação. Para a autora, isto é resultante das ações e das interações entre as pessoas que vivem ali com dinâmicas singulares e informais no cotidiano fronteiriço.

Entretanto, apesar desse caráter individualismo, no que se refere às tratativas inerentes aos recursos transfronteiriços, há uma certa similaridade entre as formas de gestão de cada país. Isso vem acontecendo por meio de acordos e tratados internacionais. No caso brasileiro, avanços adicionais têm sido alcançados com estudos direcionados e com a criação de câmaras técnicas especificas (como a CTGRHT) para a gestão de águas transfronteiriças (Brasil, 2013).

É fundamental ressaltar ainda que a adoção de medidas e normativas estabelecidas apenas na esfera macro das relações internacionais ou no posicionamento das políticas externas dos países, podem ser

TABELA 4 - Comparativo dos cenários hidropolíticos transfronteiriços no Brasil e no Paraguai.

\begin{tabular}{ll}
\hline \multicolumn{1}{c}{ BRASIL } & \multicolumn{1}{c}{ PARAGUAI } \\
\hline - Lei No 9.433/ 1997 - Lei das Águas, Política Nacional, SINGRH; & $\begin{array}{l}\text { - Lei No 3.239/ 2007 - Ley de los Recursos Hidricos del Paraguay. } \\
\text { - porém, ainda não foi regulamentada. }\end{array}$ \\
- Há uma estrutura operacional interna consolidada para gerenciar, & \\
controlar e monitorar o uso e a qualidade dos seus recursos hídricos, & - As políticas estabelecidas pelo país estão limitadas aos acordos \\
a ANA; & $\begin{array}{l}\text { internacionais, que além de dispersos têm se mostrados sem grande } \\
\text { relevância, em razão de ter identificado que o setor de gerencia- } \\
\text { mento dos recursos hídricos no país, como um todo, encontra-se } \\
\text { - Existem mecanismos para fomentar uma gestão descentralizada e } \\
\text { democrática (por meio de câmaras técnicas e comitês de bacias) que debilidades internas. } \\
\text { atuam em realidades específicas e locais, inclusive fronteiriças. }\end{array}$ \\
$\begin{array}{ll}\text { - Há incongruências normativas que podem indicar uma sobreposi- } \\
\text { ção nas atribuições e competências entre as esferas governamentais, },\end{array}$ & $\begin{array}{l}\text { - Norestadores de serviços (ESSAP/ Aguateiros/ Juntas de Saneamen- } \\
\text { pela própria CF/88. }\end{array}$ \\
$\begin{array}{ll}\text { - Aprovação do Plano Nacional de Recursos Hídricos em 2006; } \\
\text { - A deficiência em informações, a falta de políticas claras e de } \\
\text { planos para o monitoramento hídrico do país, a multiplicidade de } \\
\text { instâncias públicas e a pouca efetividade dos entes de controle e } \\
\text { regulação são os principais pontos negativos percebidos. }\end{array}$ \\
$\begin{array}{l}\text { - Existem vários acordos internacionais firmados com os países } \\
\text { vizinhos. }\end{array}$ \\
$\begin{array}{l}\text { - Existe um estudo específico sobre os recursos hídricos fronteiriços assinados alguns acordos internacionais com os países } \\
\text { e transfronteiriços (Brasil, 2013) }\end{array}$
\end{tabular}

FONTE: Elaboração própria. 
pouco efetivas. De forma especial naqueles casos em que a fronteira hídrica é contígua, como ocorre em grande parte das fronteiras internacionais na América do Sul.

A respeito deste ponto, Almeida et al. (2015) afirmam que é importante que sejam firmados acordos mais regionalizados e específicos para a realidade das fronteiras, pois assim seria possível estabelecer um gerenciamento hídrico transfronteiriço mais efetivo. Ainda, sugerem que um inventário desses recursos e a própria elaboração de comparativos dos marcos jurídicos e institucionais, acerca da gestão dos recursos hídricos, possibilitariam a prevenção de conflitos, a otimização e a repartição igualitária dos ganhos para respectivas populações e nações.

No que se refere a área de fronteira internacional entre Brasil e Paraguai, salienta-se a abundância hídrica ali existente, em águas superficiais com a Bacia do Prata e em águas subterrâneas, pelo Sistema Aquífero Guarani (SAG).

Mais especificamente, a Bacia do Prata distribui-se pelos territórios de cinco países sul-americanos da seguinte forma: i) o Brasil concentra $1.415 .000 \mathrm{~km}^{2}$ deste sistema hidrográfico, onde estão as cabeceiras dos principais rios formadores; ii) na

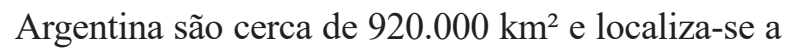
foz, o estuário do Rio da Prata; iii) o Paraguai engloba a Bacia na totalidade de seu território, o que significa $410.000 \mathrm{~km}^{2}$, localizado em sua área de drenagem; iv) a Bolívia abarca $205.000 \mathrm{~km}^{2}$; e v) o Uruguai possui $150.000 \mathrm{~km}^{2}$ da Bacia em seus respectivos territórios (Brasil, 2013). É preciso salientar que a Bacia do Prata é formada por quatro sub-bacias: do Rio Paraguai, Rio Paraná, Rio Uruguai e Rio da Prata, sendo que as duas primeiras são as maiores e são inevitavelmente compartilhadas entre Brasil e Paraguai (CIC PLATA, 2011).
Em relação às águas subterrâneas, o SIG (Figura 5) certamente é um dos maiores reservatórios de água doce do mundo, com $1.087 .879 \mathrm{~km}^{2}$ de extensão e 37 quatrilhões de litros de água (volume estimado de 37 mil km³). O Brasil ocupa cerca de $61,65 \%$ do aquífero; a Argentina, 20,98\%; o Paraguai, 8,05\%; e o Uruguai, 3,32\% (Brasil, 2013).

Em síntese, a fronteira internacional Brasil-Paraguai se estende da região de Foz do Iguaçu-PR até a região pantaneira ao Norte de Mato Grosso do Sul. Segundo Vedana (2012), essa delimitação mais específica só foi possível a partir de alguns tratados de pacificação, como o Tratado de Limites (09/01/1872) e o Tratado Complementar (21/05/1872), ambos firmados após a Guerra da Triplice Aliança. Neste espaço existem desde territórios com populações consideravéis, bem como imensos vazios demográficos. Existe, também, diversos cursos de águas, pois são cerca de $1.365,4 \mathrm{~km}$ de extensão, dos quais $928,5 \mathrm{~km}$ são por rios e 436,9 km são terrestres (Vedana, 2012; FUNAG, 2019).

É necessário ressaltar que no contexto das relações políticas direcionadas aos recursos hídricos que são compartilhados entre estes dois países, apesar de atualmente existir certo grau de cooperação, no passado as mesmas já resultaram em situações de conflitos que ocorreram justamente em suas áreas de fronteira.

Segundo Ribeiro (2017, p. 269), "são registrados cerca de 60 documentos bilaterais envolvendo Brasil e Paraguai, alguns dos quais surgiram ainda no Império. Entretanto, em 1966 foi assinada a Ata de Iguaçu, que constituiu uma base importante nas relações entre os dois países", em que pode se observar uma evolução nas discussões sobre o uso dos recursos hídricos na fronteira Brasil e Paraguai, as quais estão relacionadas puramente a questões energéticas e aspectos econômicos para o desenvolvimento das nações. 


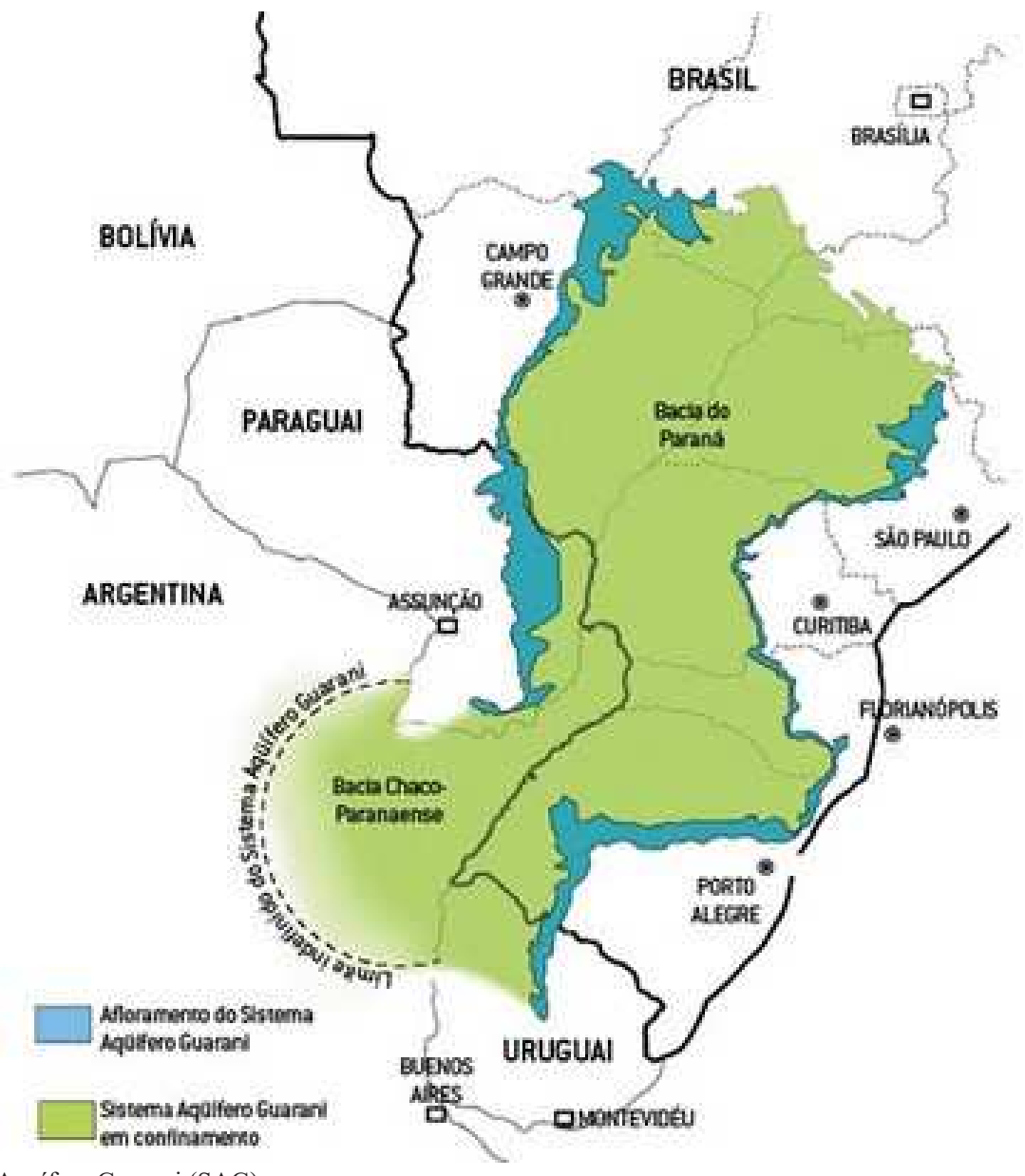

FIGURA 5 - Sistema Aquífero Guarani (SAG).

Fonte: <http://www.cprm.gov.br> acesso em: fev. 2019.

$\mathrm{O}$ autor analisa detalhadamente as particularidades no Tratado de Itaipu, o principal acordo firmado entre Brasil e Paraguai sobre o uso das águas transfronteiriças. Ele conclui que os dois países ainda não possuem uma efetiva cooperação internacional para o uso compartilhado de seus recursos hídricos, pois a existência de tensões nas relações entre esses dois países é condicionada à fatores relacionados com a incessante busca pela hegemonia hídrica e a soberania energética,

[...] a situação entre Brasil e Paraguai em relação ao uso da água transfronteiriça ainda está longe de uma cooperação sem conflitos. [...] podem surgir novas demandas pelas partes que não conseguem estabelecer um plano de uso da água duradouro que atenda aos interesses da maior parte da população dos dois 
países. Por isso a cooperação entre Brasil e Paraguai para exploração do potencial hidrelétrico do rio $\mathrm{Pa}$ raná pode ser entendida como incompleta e sujeita a novos focos de tensão no médio prazo (Ribeiro, 2017, p. 272-273).

Por outro lado, Machado (2017) afirma que, atualmente, em países com grande abundância hídrica, como é o caso do Brasil e do Paraguai, as águas transfronteiriças são tratadas de forma remota devido à ausência de conflitos, sendo que as disputas pelo seu uso são solucionadas por meio de acordos pacíficos e diplomáticos. Não obstante, cabe salientar que diante da interdependência hidrológica, do aumento demográfico e da importância econômica-social inerente aos recursos hídricos para o desenvolvimento das nações, existe certa preocupação de que mesmo territórios com abundância hídrica se tornem suscetíveis aos problemas hídricos.

Martinez (2012) afirma que com o cenário hídrico interdependente e vulnerável:

[...] é crescente a preocupação com o potencial surgimento de tensões e conflitos entre comunidades ou mesmo entre países que compartilham corpos hídricos de forma transfronteiriça. A condição transfronteiriça das fontes de água, [...] impõe aos Estados nacionais uma atenção e vigilância redobrada, com vistas à prevenção dos impactos negativos que possam alterar as condições físico-químicas das águas nos outros países com os quais compartilha um determinado corpo hídrico, de forma a evitar maiores tensões hidro ambientais, assim como também potenciais conflitos de repercussão social e política (Martinez, 2012, p. 79).

Além disso, atualmente, depara-se com a inexistência de uma estrutura institucional equivalente que regule os caudais de água que atravessam fronteiras, como ocorre no Brasil e no Paraguai, o que pode ter implicações mais profundas;
[...] pois à medida que a água for escasseando relativamente à procura, a competição transfronteiriça pela partilha dos rios e de outros recursos hídricos também irá aumentar. Sem mecanismos institucionais capazes de responder a estes problemas transfronteiriços, esta competição poderá conduzir a conflitos insanáveis (PNUD, 2006, p. 206).

Na ocorrência destas situações, a vulnerabilidade geográfica imposta às cidades limítrofes poderá sofrer maiores complicações, pois essa proximidade internacional ainda implica em uma série de preocupações que se relacionam com questões relacionadas à segurança nacional. Dessa forma, com a iminência de uma escassez hídrica, os conflitos políticos podem acentuar-se em cidades fronteiriças em razão de que estes são locais em que a contiguidade geográfica instaura maior interdependência e vulnerabilidade com o país vizinho do que com o próprio interior (Wong-González, 2005).

Nesse sentido, Brito \& Missio (2019) apontam que nos municípios conurbados internacionalmente, a duplicidade na natureza das instituições exige um planejamento territorial específico sobre os recursos naturais pois estes estão distribuídos além dos limites geográficos e jurisdicionais. Os autores afirmam que nestes locais existe, inevitavelmente, uma dicotomia política que implica diretamente no direito de propriedade e na soberania das nações.

Mais especificamente, no caso das cidades localizadas na área de fronteira internacional é fundamental considerar todo o histórico das relações políticas entre os países, pois isso pode intensificar o surgimento de conflitos.

Outro aspecto relevante é que os governantes locais precisam lidar com problemas incomuns, que não possuem regulamentação específica e, como no caso da gestão das águas transfronteiriças, se agrava 
quando a resolução está condicionada à responsabilidade da esfera federal dos países (Brito, 2018). Portanto, tais indefinições institucionais em torno do gerenciamento hídrico transfronteiriço, tanto no Brasil como no Paraguai, colocam "em xeque" as ações políticas pacíficas construídas e os pressupostos da hidropolítica. Isso pode afetar de forma direta as relações políticas, em especial, nas fronteiras, mas também as relações locais.

\section{Considerações finais}

A análise da estrutura jurídica-legal acerca das águas transfronteiriças entre Brasil e Paraguai e dos principais aspectos da gestão hídrica desses países mostram que: i) apesar de algumas similaridades administrativas internas, não existem normativas específicas, tanto no Brasil como no Paraguai, para uma efetiva gestão hídrica compartilhada; ii) o aparato institucional adotado é individualizado a fim de manter a soberania de cada país; iii) no Paraguai, existem incongruências e fragilidades internas que podem refletir nas relações exteriores com seus vizinhos; iv) no Brasil, apesar da consolidada estrutura interna, há uma sobreposição de responsabilidades entre as esferas governamentais; e v) em termos de gerenciamento dos recursos hídricos transfronteiriços os países encontram-se em estágios distintos.

Nesse contexto, somado às historicidades entre Brasil e Paraguai, é possível afirmar que o panorama hidropolítico nas áreas de fronteira é frágil. $\mathrm{E}$, da mesma forma, que a sua sustentação se baseia amplamente no fato de que os recursos hídricos são abundantes na fronteira entre esses países. Assim, é fundamental compreender que a proximidade geográfica e a iminência da escassez hídrica são aspectos que precisam ser amplamente debatidos e que as normativas legais e tratativas jurídicas precisam anteceder aos conflitos e impasses que podem surgir acerca da gestão hídrica. É preciso, portanto, avançar nessa direção.

De forma sintética, conclui-se que existem fragilidades nas relações entre os dois países, que somadas à interdependência hidrológica e a importância dos recursos hídricos na atual conjuntura ambiental, tornam o futuro do panorama hidropolítico destes países vulneráveis e instáveis, especialmente nas áreas dessa fronteira internacional.

\section{Agradecimentos}

Os autores agradecem o apoio financeiro da CAPES e CNPq.

\section{Referências}

ABC-Associação Brasileira de Ciências. Recursos hídricos no Brasil: problemas, desafios e estratégias para o futuro. José Galizia Tundisi (coord.). Rio de Janeiro, 2014.

Abente, D. The War of the Triple Alliance: Three Explanatory Model. Latin American Research Review, 22(2), 47-69, 1987.

Almeida, B. R. de; Castro, E. L. de F.; Ribeiro, M. R. de S. Recursos Hídricos Transfronteiriços no Mercosul: Sustentabilidade, Gestão Compartilhada e Cooperação Internacional. Revista de la Secretaría del Tribunal Permanente de Revisión, 3(5), 355-389, 2015. Disponível em: http://scielo.iics.una.py/scielo.php?script=sci_arttext\&pi$\mathrm{d}=\mathrm{S} 2304-78872015000500355$.

ANA - Agência Nacional de Águas. Conjuntura dos recursos hídricos no Brasil 2017: Relatório pleno. Brasília, 2017.

ANA - Agência Nacional de Águas. O que é o SNIRH? Disponível em: http://www3.ana.gov.br/portal/ANA/ges- 
tao-da-agua/sistema-de-gerenciamento-de-recursos-hidricos/o-que-e-o-singreh. Acesso em: abr. 2018.

Brasil. Lei no 9.433, de 8 de Janeiro de 1997. Institui a Política Nacional de Recursos Hídricos, cria o Sistema Nacional de Gerenciamento de Recursos Hídricos regulamenta o inciso XIX do art. 21 da Constituição Federal. Brasília: 1997.

Brasil. Senado Federal/Coordenação de Edições técnicas. Constituição da República Federativa do Brasil. Brasília: 2008.

Brasil. Presidência da República/Secretaria de Assuntos Estratégicos. Água e Desenvolvimento Sustentável: Recursos Hídricos Fronteiriços e Transfronteiriços do Brasil. Brasília: DF, 2013.

Brito, A. R. Gestão de Políticas Públicas para Bens Comuns em Território Fronteiriço: o caso de Ponta Porã (BR) e Pedro Juan Caballero (PY). Ponta Porã. Dissertação (Mestrado em Desenvolvimento Regional e de Sistemas Produtivos) - Universidade Estadual de Mato Grosso do Sul, 2018.

Brito, A. R.; Missio, F. J. Planejamento territorial em cidades gêmeas. Revista Brasileira de Gestão e Desenvolvimento Regional, 15(6), edição especial, 52-63, 2019. Disponível em: https://www.rbgdr.net/revista/index.php/rbgdr/article/ view/5184.

Broch, S. A. O. Gestão transfronteiriça de águas: o caso da Bacia do Apa. Brasília. Tese (Doutorado em Desenvolvimento Sustentável) - Universidade de Brasília, 2008.

Carneiro Filho, C. P. Processos de Transfronteirização na Bacia do Prata: a Tríplice Fronteira Brasil-Argentina-Paraguai. Porto Alegre. Tese (Doutorado em Geografia) - Universidade Federal do Rio Grande do Sul, 2013.

CIC PLATA - Comitê Intergovernamental Coordenador dos países da Bacia do Prata. Programa para a Gestão Sustentável dos Recursos Hídricos da Bacia do Prata, considerando os efeitos decorrentes da variabilidade $e$ mudança do clima. Março, 2011.

CNRH - Conselho Nacional de Recursos Hídricos. Resolução $N^{\circ} 10$ de 21 de Junho de 2000. Institui, a Câmara Técnica Permanente de Gestão dos Recursos Hídricos Transfronteiriços, de acordo com os critérios estabelecidos no Regimento Interno do Conselho Nacional de Recursos
Hídricos. Brasília: 2000.

Crespo, A.; Luraghi, O. M. Informe nacional sobre la gestion del agua em Paraguay. 2000. Disponível em: https:// www.cepal.org/DRNI/proyectos/samtac/InPa00100.pdf. Acesso em nov. 2017.

Doratioto, F. Relações Brasil-Paraguai: afastamento, tensões e reaproximação (1889-1954). Brasília: FUNAG, 2012.

Facetti, J. F. La reforma del sector hídrico en el Paraguay: una tarea inconclusa. Debate. Revista digital de políticas públicas. 2014.

Fernández, D.; Aguilera, C. A.; Bóbeda, J.; Giménez, J. Plan estratégico sectorial de água y saneamento de Paraguay. BID - Banco Interamericano de Desarrollo/Setor de Infraestrutura y Medio Ambiente. Nota técnica $n^{\circ} 115$, 2010. Disponível em: https://publications.iadb.org/es/ publicacion/15960/plan-estrategico-sectorial-de-agua-potable-y-saneamiento-de-paraguay. Acesso em: nov. 2017.

Ferres, V. P. A solução do conflito de Itaipu como início da cooperação política Argentino-Brasileira na década de 80. Projeto História. (29 - tomo 2), p. 661-672. São Paulo, dez. 2004. Disponível em: https://revistas.pucsp.br/revph/ article/view/9989/0.

Folegatti, M. V.; Sánchez-Román, R. M.; Coelho, R. D.; Frizzone, J. A. Gestão dos recursos hídricos e agricultura irrigada no Brasil. In: Bicudo, C. E. de M.; Tundisi, J. G.; Scheuenstuhl, M. C. B. (Orgs.). Águas do Brasil: análises estratégicas. São Paulo: Instituto de Botânica, 2010.

FUNAG - Fundação Alexandre de Gusmão. 2018. Brasil: fronteiras terrestres. Disponível em: http://www.funag.gov. br/ipri/images/informacao-e-analise/fronteiras-terrestres-brasil.pdf. Acesso em fev. 2019.

FUNDAINGE - Fundación para el Desarrollo de la Ingeniería. Vision de los recursos hídricos en Paraguay. Domecq, R. M. (Org.). CIC, Informe Final. Julho de 2004.

Gemelli, V.; Souza, E. B. C. A regionalização na fronteira Brasil/Paraguai. In: Anais do I Sem. Internacional dos espaços de fronteira, III Seminário Regional sobre território, fronteira e cultura, VII Expedição geográfica da UNIOESTE. Marechal Candido Rondon, 2011.

Guerra, S. C. S. Direito Internacional Ambiental: breve 
reflexão. Revista Direitos Fundamentais \& Democracia, 2(2), 2007.

Guimarães, G. de S.; Souza, E. B. C. de. A Ponte Internacional da Amizade: As Múltiplas Territorialidades entre Brasil e Paraguai. In: Anais do XVI Encontro Nacional dos geógrafos. Realizado nos dias 25 a 31 de julho de 2010. AGB, Porto Alegre, 2010.

GWP - Global Water Patrnership (Parceria Mundial pela Água). O Direito Internacional de águas na América Latina: Manual de capacitação. Rede Latino-americana de Desenvolvimento de Capacitação para a Gestão Integrada da Água, Programa das Nações Unidas (PNUD). Montevideo-Uruguai. Mar./2015.

GWP/SAMTAC - Global Water Partnership/Comité Asesor Técnico de Sud América. Lineamientos para la Política Nacional de Recursos Hídricos. Iniciativa para la gestión integrada de los recursos hídricos en Paraguay. Asunción: 2005

Haurón, J. V.; Figueredo, V. M. P; Nasich, M. R.; Cruz, M. A. S. S. La gobernabilidad y la gestión de cuencas. In: Anais do VIII Simpósio Iberoamericano em Comércio Internacional e Integração Regional. Universidade Federal da Fronteira Sul, 2017.

Itaipu. Nossa História. Disponível em: https://www.itaipu. gov.br/nossahistoria. Acesso em jan. 2018.

Machado, R. Q. Águas transfronteiriças: aspectos jurídicos e ambientais. Revista Eletrônica Multidisciplinar-FACEAR, 1(6), 1-11, 2017. Disponível em: http://revista.facear.edu. br/artigo/ \$aguas-transfronteiricas-aspectos-juridicos-e-ambientais.

Martinez, M. M. Interdependência Hidrológica, Incipiente Regime Regional e Baixo Conflito. Tese (Doutorado em Relações Internacionais) - Universidade de Brasília, 2012.

MMA/SRHU - Ministério do Meio Ambiente/Secretaria de Recursos Hídricos e Ambiente Urbano. Águas Subterrâneas: um recurso a ser conhecido e protegido. Brasília: 2007. Disponível em: http://www.mma.gov.br/estruturas/167/publicacao/167_publicacao28012009044356.pdf. Acesso em maio. 2018.

MMA - Ministério do Meio Ambiente. Informações sobre o SINGRH. 2018. Disponível em: http://www.mma.gov.br/ agua/recursos-hidricos/sistema-nacional-de-gerenciamento-de-recursos-hidricos. Acesso em: maio. 2018.

MOPC - Ministerio de Obras Públicas y Comunicaciones. Plano Estratégico 2012-2015. Dirección de agua potable y saneamiento (DAPSAN).Versión 4. Outubro, 2012. Disponível em: http://www.py.undp.org/content/dam/paraguay/ docs/7Compliado\%20DAPSAN\%20pdf.pdf. Acesso em: fev. 2019.

Mota, C. G. História de um silêncio: a guerra contra o Paraguai (1894-1870) 130 anos depois. Estudos avançados, 9(24), 243-254, 1995. Disponível em: http://www.scielo.br/scielo. php?script=sci_arttext\&pid=S0103-40141995000200012

Muller, K. M. Espaços de fronteira nacionais, polos de integração. In: Oliveira, T. C. M. (Org.). Território sem limites: estudos sobre fronteiras. Campo Grande: Editora UFMS, p. 573-592, 2005.

Oliveira, T. C. M. de. Condições de conurbação internacional: o caso Corumbá- Puerto Quijarro- Puerto Suárez. In: Osório, A. C. do N.; Pereira, J. H. do V; Oliveira, T. C.M. (Orgs.). América Platina: educação, integração e desenvolvimento territorial. Campo Grande, MS: Editora UFMS, p. 233-254, 2008.

Paraguay. Constitución de la República de Paraguay publicado en el día 20 de junio de 1992. Asunción: 1992.

Paraguay. Ley de los Recursos Hidricos del Paraguay. Congreso de la nación paraguaya sanciona la Ley $n^{\circ} 3.239$ en el día 10 de julio de 2007.

PNUD - Programa das Nações Unidas para o Desenvolvimento. Relatório do Desenvolvimento Humano 2006. A água para lá da escassez: poder, pobreza e a crise mundial da água. New York: 2006.

Queiroz, F. A. de. A hidropolítica Platina no contexto do complexo regional de Segurança da América do Sul: entre o conflito e a cooperação. Contexto Internacional, 34(2), 573-616, 2012. doi: 10.1590/S010285292012000200007

Ribeiro, W. C. Uso compartilhado da água transfronteiriça na Bacia do Prata: Utopia ou Realidade? Ambiente \& Sociedade, 20(3), 263-276, 2017. Disponível em: http://www. scielo.br/pdf/asoc/v20n3/pt_1809-4422-asoc-20-03-00257. 
pdf

Souza, M; Versieux, B. H. O Brasil na governança de recursos hídricos transfronteiriços: o papel da Agência Nacional de Águas na gestão da bacia Amazônica. Carta Internacional. Publicação da Associação Brasileira de Relações Internacionais. Vol. 10, edição especial, 114-132, 2015. doi: 10.21530/ci.v10n3.2015.300

Salas Dueñas, D. A. Análisis de la problemática del agua en Paraguay. Revista Memorias del Instituto de Investigaciones en Ciencias de la Salud, 13(1), 97-103, 2015. doi: 10.18004/ Mem.iics/1812-9528/2015.013(01) 97-103

Sola, F. Direito Internacional Ambiental da Bacia do Prata. $1^{\text {a }}$ edição. Curitiba: Gedai/UFPR, 2015.

Tatemoto, L. C. B. Poder e conflito em Bacias Hidrográficas Internacionais. Belo Horizonte, Dissertação (Mestrado em Relações Internacionais) - Pontifícia Universidade Católica de Minas Gerais, 2011.
Tucci, C. E. M.; Hespanhol, I.; Cordeiro Netto, O. de M. Gestão da água no Brasil. Brasília: UNESCO, 2001.

UNESCO/OEA - Organización de las naciones unidas para la Educación, la ciencia y la cultura/ Organización de los Estados Americanos. Marco Legal e Institucional en la Gestión de los Sistemas Acuiferos transfronterizos en las Américas. Serie ISARM Américas nº 2. Montevideo: 2008.

Vedana, T. E. A fronteira Brasil-Paraguai, problemas e a situação hídrica, perspectiva para uma gestão contemporânea. Contribiciones a las Ciencias Sociales. (online) mai./2012. Disponível em: http://www.eumed.net/rev/cccss/20/tev. html. Acesso em: fev. 2019.

Wong-González, P. Cooperación y competencia internacional de regiones: hacia nuevas formas de gestión de desarrollo regional binacional. In: Oliveira, T. C. M. (Org.). Território sem limites: estudos sobre fronteiras. Campo Grande: Editora UFMS, p. 155-194, 2005. 


\section{Apêndice 1:}

Marco jurídico-legal, nacional e estadual, sobre os recursos hídricos transfronteiriços

\section{NO ÂMBITO NACIONAL}

- Lei n⿳ 9.433, de 8 de janeiro de 1997: Conhecida como a Lei das águas, instituiu a Política Nacional de Recursos Hídricos (PNRH), cria o Sistema Nacional de Gerenciamento de Recursos Hídricos (SINGRH).

- Lei n⿳0 9.984, de 17 de julho de 2000: Dispôs sobre a criação da Agência Nacional de Águas (ANA), entidade federal de implementação da Política Nacional de Recursos Hídricos e de coordenação do SINGRH.

- Plano Nacional de Recursos Hídricos (PNRH): é um dos instrumentos que orienta a gestão das águas no Brasil. Tem como objetivo principal estabelecer um pacto nacional para a definição de diretrizes e políticas públicas voltadas para a melhoria da oferta de água, em quantidade e qualidade, gerenciando as demandas e considerando ser a água um elemento estruturante para a implementação das políticas setoriais, sob a ótica do desenvolvimento sustentável e da inclusão social. Embora tenha sido aprovado em 2006, ele é adequado periodicamente às realidades das Regiões Hidrográficas, por revisões que aperfeiçoam e aprofundam temas a partir de análises técnicas e de consultas públicas.

- Resoluções do Conselho Nacional de Recursos Hídricos (CNRH) que tratam de temas fronteiriços:

- $\quad N^{0} 10$, de 21 de julho de 2000; institui a Câmara Técnica Permanente de Gestão dos Recursos Hídricos Transfronteiriços - a CTGRHT.

- $\quad \quad \quad \quad N^{\circ} 15$, de 11 de janeiro de 2001; estabelece diretrizes gerais para a gestão de águas subterrâneas.

- $\quad \mathrm{N}^{\mathrm{o}} 32$, de 15 de outubro de 2003; institui a Divisão Hidrográfica Nacional.

- $\quad N^{0} 58$, de 2 de junho de 2006; aprova o Plano Nacional de Recursos Hídricos.

- $\quad \mathrm{N}^{\mathrm{o}}$ 80, de 10 de dezembro de 2007; aprova o Detalhamento Operativo de Programas do Plano Nacional de Recursos Hídricos.

- Moções do Conselho Nacional de Recursos Hídricos (CNRH) que tratam de temas fronteiriços:

- $\quad$ No 9, 14 de março de 2002; solicita solução dos problemas causados pela poluição, decorrente da falta de saneamento, da bacia do rio Quaraí, fronteira do estado do Rio Grande do Sul com o Uruguai.

- $\quad \mathrm{N}^{\circ} 14$, de 11 dezembro de 2002; solicita ações referentes aos problemas existentes na bacia do rio Apa.

- $\quad$ No 29, de 29 outubro de 2004; recomenda a implantação de Projeto Piloto de Gestão Integrada e Sustentável de Recursos Hídricos e Ambiental nas Bacias Transfronteiriças da Lagoa Mirim e do Rio Quaraí.

- $\quad$ No 48; de 25 de maio de 2009; recomenda a formação de uma estrutura nacional para, de forma continuada e articulada, em especial com os Estados abrangidos pelo Aquífero Guarani, coordenar e acompanhar o processo de cooperação nacional e regional e as ações e atividades geradas pelo Projeto de Proteção Ambiental e Desenvolvimento Sustentável do Sistema Aquífero Guarani - PSAG.

\section{NO ÂMBITO ESTADUAL - Definição das Políticas Estaduais de Recursos Hídricos}

Acre: Lei ${ }^{\circ} 1500$, de 15 de julho de 2003.

Amazonas: Lei $\mathrm{n}^{\circ} 2.712$, de 28 de dezembro de 2001.

Amapá: Lei $n^{\circ} 686,07$ de julho de 2002.

Mato Grosso: Lei n ${ }^{\circ} 6.945$ de 05 de novembro de 1997.

Mato Grosso do Sul: Lei no 2.406, 29 de janeiro de 2002, e a Lei № 3.183, de 21 de fevereiro de 2006.

Pará: Lei $n^{\circ} 6.381,25$ de julho de 2001.

Paraná: Lei no $12.726,26$ de dezembro de 1999.

Rio Grande do Sul: Lei no 10.350, 30 de dezembro de 1994 e Lei n ${ }^{\circ} 8.850$, de 8 de maio de 1989.

Rondônia: Lei Complementar no 255 , de 25 de janeiro de 2002.

Roraima: Lei ${ }^{\circ}$ 547, de 23 de junho de 2006.

Santa Catarina: Lei n ${ }^{\circ} 9.022$ de 06 de maio de 1993 e Lei n ${ }^{\circ}$ 9.748, de 30 de novembro de 1994.

Fonte: Adaptado de Brasil (2013). 


\section{Apêndice 2:}

Síntese de acordos, tratados e convênios internacionais no Brasil.

- Convênio de Cooperação para um estudo relativo ao uso de Energia Hidroelétrica dos rios Acaray e Monday (20/01/1956) entre Brasil e Paraguai.

- Tratado da Bacia do Plata de 1969 (23/04/69) Argentina - Bolívia - Brasil - Paraguai - Uruguai que tem como finalidade permitir o desenvolvimento harmônico e equilibrado e o aproveitamento dos recursos naturais da região e assegurar sua preservação mediante a utilização racional desses recursos;

- Tratado sobre Soberania Compartilhada entre Brasil e Paraguai a partir do Salto Grande de Sete Quedas ou de Guaíra até Foz de Iguaçu (26/04/73) sobre o aproveitamento hidroelétrico dos recursos hídricos do Rio Paraná, pertencentes ao domínio dos dois países, desde Salto Grande de Sete Quedas ou Salto de Guaíra até a Foz do rio Iguaçu;

- Tratado de Cooperação para o aproveitamento dos recursos naturais e o Desenvolvimento da Bacia da Lagoa Mirim e o Protocolo para o aproveitamento dos Recursos Hídricos da seção limítrofe do Rio Yaguarón (17/2/78), anexo ao Decreto 81.351, entre Brasil e Uruguai;

- Tratado de Cooperação Amazônica de 1978 (30/07/78) entre Bolívia, Brasil, Colômbia, Equador, Guiana, Peru, Suriname e Venezuela, promulgado no Brasil pelo Decreto $N^{\circ} 85.050$ de 18/8/1990; promove o desenvolvimento harmônico dos territórios amazônicos, com preservação do meio ambiente, conservação do uso racional dos recursos naturais, da pesquisa científica e o intercâmbio de informações entre os países.

- Tratado Brasil-Argentina para o Aproveitamento dos Recursos Hídricos Compartilhados nas seções limítrofes do Rio Uruguai e seu afluente o Rio Pepirí-Guazú (17/5/80), incluindo hidroelétricos, melhoria nas condições de navegabilidade do Rio Uruguai nesses trechos, atenuação dos efeitos de cheias extraordinárias e a utilização racional das águas para usos consuntivos.

- Acordo de Cooperação entre Brasil e Uruguai para o Aproveitamento dos Recursos Naturais e o Desenvolvimento da Bacia do Rio Quaraí (11/3/91), estabelece que esses países se comprometem a alcançar e expandir uma cooperação com o objetivo de promover o desenvolvimento do Rio Quaraí. Entre outros objetivos indica a melhoria das condições socioeconômicas dos habitantes da bacia, o uso equitativo e seguro da água para fins domésticos, urbanos, agrícolas e industriais; a regulação dos cursos de águas e controle de inundações, solucionar problemas devido ao uso inadequado da água, produção, distribuição e uso da hidroeletricidade e outras formas de geração de energia; o incentivo à navegação ou outros meios de transportes e comunicação; o desenvolvimento de projetos específicos de interesses mútuos; gestão, uso adequado, recuperação e conservação de recursos hídricos tomando em consideração suas características, entre outros;

- Tratado de Chuí, firmado em 11/3/1991, entre Brasil e Uruguai. Estabelece um acordo de cooperação na área dos recursos hídricos, como complemento a um acordo prévio de cooperação técnica e científica básica;

- Acordo Marco sobre Meio Ambiente do MERCOSUL (22/06/01) Argentina, Brasil, Paraguai e Uruguai, promulgado no Brasil pelo Decreto ${ }^{\circ} 5.208$ de 17/12/2004, promovendo a cooperação para a proteção do meio ambiente e o uso sustentável dos recursos naturais para melhorar o nível de vida e o desenvolvimento sustentável;

- Acordo de Cooperação para o desenvolvimento sustentável e a gestão integrada da Bacia Hidrográfica do Rio Apa, entre Brasil e Paraguai (11/9/2006), objetivando promover o desenvolvimento sustentável e a gestão integrada dos recursos hídricos fronteiriços.

- Projeto de Proteção Ambiental e Desenvolvimento Sustentável do Sistema Aquífero Guarani (SAG), entre a Argentina, Brasil, Paraguai e Uruguai, foi assinado por meio do Acordo sobre o Aquífero Guarani no dia 2 de agosto de 2010, durante reunião do Conselho Mercado Comum do Mercosul com o objetivo principal de ampliar as ações conjuntas para a conservação e aproveitamento sustentável dos recursos hídricos desse reservatório.

- Outros acordos bilaterais:

- Brasil e Uruguai: Tratado de Amizade, Cooperação e Comércio (12/6/75), Acordo Básico de Cooperação Científica e Técnica (12/6/75), Acordo de Pesca e Preservação de Recursos Vivos de 1969, Acordo referente ao transporte fluvial e lacustre (Rivera, 12/06/1975).

- Brasil e Argentina: Acordo de Cooperação Científica e Tecnológica. Concluído em Buenos Aires no dia 17 de maio de 1980 (que entrou em vigor dia 18/08/82).

- Brasil e Colômbia: Acordo para a Conservação da Flora e da Fauna dos territórios Amazônicos, promulgado pelo Brasil em 12/7/06. 
- Organizações Binacionais e outros:

- Comissão Mista Brasileira - Uruguaia para o Desenvolvimento da Lagoa Mirim (SB/CLM) que foi estabelecida por meio de intercâmbio de correspondências, constituindo um acordo, firmado em 26/04/63 entre Brasil e Uruguai visando a realização de projetos conjuntos de desenvolvimento econômico e social, bem como de promover o integral aproveitamento dos recursos das áreas limítrofes de acordo com critérios equitativos, o que foi regulamentado pelo Decreto ${ }^{\circ}$ 4.258, 4 de junho de 2002;

- Comissão Mista Brasileiro-Paraguaia para o Desenvolvimento Sustentável e a Gestão Integrada da Bacia Hidrográfica do Rio Apa, criada através do acordo entre Brasil e Paraguai no dia 11 de setembro de 2006 sobre o Rio Apa, com a competência de identificar iniciativas e projetos de interesses bilaterais, seja na identificação de áreas de interesse comum e/ou na realização de estudos, programas e obras para, por exemplo, utilizar a água de forma racional e a preservar o ecossistema aquático.

- Em relação à Bacia da Prata, foi instituído pelo Tratado correspondente o Comité Intergovernamental da Bacia do Prata (CIC PLATA) em 1969. As funções do CIC, em linhas gerais (determinadas no art. III do Tratado) especifica-o como órgão permanente da Bacia e o responsável por promover, coordenar e permanecer no caminho de ações multinacionais que tenham como objetivo o desenvolvimento da Bacia do Prata, a assistência técnica e financeira que organize com o apoio dos organismos internacionais e que estime conveniente, executando as decisões que adotem os ministros das Relações Exteriores.

Fonte: Elaboração própria com base na Pesquisa Documental. 


\section{Apêndice 3:}

Síntese de acordos, tratados e convênios internacionais do Paraguai

- O Tratado de Cooperação da Bacia do Prata (1969), firmado entre os países Argentina, Bolívia, Brasil, Paraguai e Uruguai. Por meio desse tratado criou-se o Comitê Intergovernamental Coordenador dos países da Bacia do Rio Prata (CIC PLATA). Além disso, isso resultou em diversos acordos, convênios e negociações entre tais países, como:

- Em 1973, com a Lei nº 389/73 negocia-se o Tratado para a Construção e Administração da Represa de Itaipu; e, com a Lei n ${ }^{\circ}$ 433/73, o Tratado para a Construção e Administração da Represa de Yacycretá;

- Em 1993, o Acordo de Transporte Fluvial pela Hidrovia Paraguai - Paraná (Porto de Cáceres - Puerto de Nueva Palmira);

- Em 1995, o Acordo Constitutivo da Comissão Trinacional para o Desenvolvimento da Bacia do Pilcomayo, firmados no dia 9 de fevereiro entre Argentina, Bolívia e Paraguai;

- Em 1996, firma-se o Convênio sobre Conservação e Desenvolvimento dos recursos pesqueiros nas áreas limítrofes dos rios Paraná e Paraguai, com a República da Argentina;

- Em 2000, o Acordo para a Conservação da Fauna Aquática nos cursos dos rios limítrofes entre o Paraguai e o Brasil, e seu protocolo Adicional (Lei n $\left.{ }^{\circ} 1572 / 00\right)$;

○ Em 2003, assinou-se o Acordo de Cooperação para o Desenvolvimento Sustentável e a Gestão Integrada da Bacia hidrográfica do Rio Apa, entre Brasil e Paraguai (Lei nº 3465/2008).

- O Tratado de Itaipu (Brasil e Paraguai), firmado no dia 26 de abril de 1973 objetivando o aproveitamento hidroelétrico dos recursos hidráulicos do Rio Paraná. Com esse tratado foi constituída a entidade binacional Itaipu, tendo como representantes do Brasil a ELETROBRÁS (Centrais Elétricas Brasileiras S.A. - uma sociedade anônima de economia mista brasileira) e do Paraguai, a ANDE (Administración Nacional de Eletricidad - uma entidade autárquica paraguaia).

- O Tratado de Yacycretá (Argentina e Paraguai), firmado do dia 26 de março de 1974, objetiva o melhoramento das condições de navegabilidade, fomentando o aproveitamento hidrelétrico e a atenuação dos efeitos predatórios das enchentes causadas por inundações extraordinárias. Para isso, constituiu-se a Entidade Binacional Yacyretá (E.B.Y.) com capacidade jurídica, financeira e administrativa, sendo a responsável técnica no estabelecimento de estudos, projetos, desde a direção até a execução técnica e econômica das obras.

- $\quad$ No dia 13 de janeiro de 2003, em Washington, foi firmado por um memorando de Entendimento entre a República do Paraguai e a Secretaria Geral da Organização dos Estados Americanos (OEA) para a execução do projeto Proteção Ambiental e Desenvolvimento Sustentável do Sistema Aquífero Guarani (SAG). O projeto conta com a participação ainda dos demais países que compartilham o SGA (Argentina, Brasil e o Uruguai) tendo como principal objetivo, a elaboração e a implementação de um marco adequado e funcional para o manejo do SGA. Esse marco deve estar baseado em uma orientação que dissemine o aspecto institucional, legal, científico, econômico e técnico visando oferecer uma estrutura administrativa e de apoio para que o manejo seja coordenado para harmonizar as políticas de águas entre os países e, assim, reduzir ameaças ${ }^{1}$.

FONTE: Elaboração própria com base na Pesquisa

${ }^{1}$ Mais informações em: <http://www.oas.org/DSD/WaterReso+urces/Pastprojects/Guarani_esp.asp> Acesso em jan. 2018. 